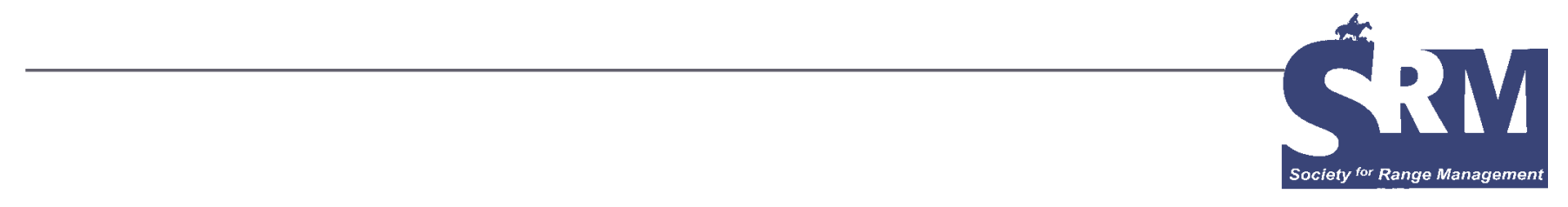

\title{
What's Limiting: Quality or Quantity?
}

\section{Can cattle standing in belly-deep grass actually be hungry?}

\section{By Robert K. Lyons and Richard V. Machen}

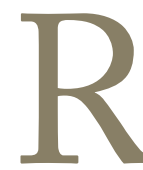

ange cattle performance depends on both forage quality and forage quantity. A simple, effective set of tools is available to cattlemen to help detect performance.

Nutritional computer models have been developed to estimate beef cattle performance. Fox ${ }^{1}$ suggested that these models require 1) adequate information and 2) user understanding to adjust models to ranch levels. In other words, models can be calibrated to a ranch.

On rangelands, forage intake information is difficult to obtain. Estimating total forage standing crop is possible.

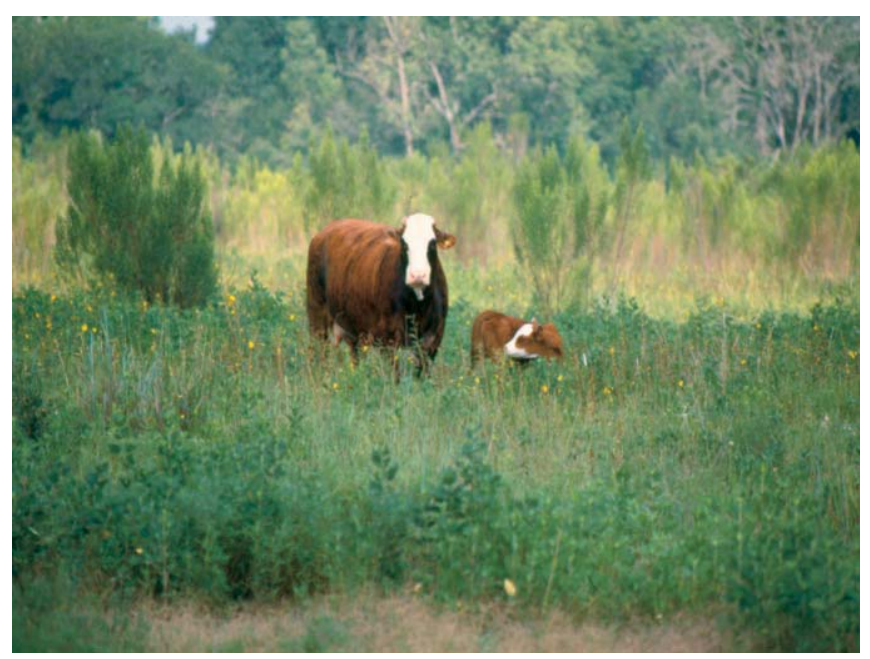

Grazing cattle need both adequate forage quality and forage quantity.
However, predicting how much of the available forage grazing animals will consume is difficult. Studies report $80 \%$ of grazed diets coming from $1 \%$ of the standing crop in Australia $^{2}$ to $6 \%$ of the standing crop in Oregon ${ }^{3}$ and $85 \%$ from 2 grasses during 3 seasons in Texas. ${ }^{4}$ In South Africa ${ }^{5}$ least-preferred species were grazed only when $80 \%$ to $100 \%$ of preferred and intermediate grasses were defoliated.

Animal performance can be used to estimate forage intake on a group or pasture basis ${ }^{6}$ and with grazing, lactating dairy cattle. ${ }^{7}$ This project investigated the use of tools to 1) improve computer model performance estimates and 2) separate forage quality from forage quantity problems.

\section{What We Did}

How Good is the Forage?

This project involved 6 cow-calf herds on 5 ranches in 5 Texas counties from 1997 to 2004 . Each ranch was initially scheduled for a 2-year study. One ranch participated for 1 year, 3 for 2 years, and 1 ranch with 2 herds for 3 years.

Forage diet quality was estimated from near infrared reflectance spectroscopy (NIRS) analysis of composite fecal samples taken each month of the study on each ranch. A composite fecal sample consisted of subsamples from about 10 different cows. Ranch personnel selected a specific day of the month that was convenient to condition-score cows (using the 1-9 system) and collected fecal samples. All subsequent samples were taken within 5 days of this day of the month. In all but one herd, cows were condition scored by ranch personnel. In this herd, cows were condition scored by extension personnel. Samples were analyzed at the Grazing Animal Nutrition Lab at Texas A\&M University 


\section{Body Condition Score (BCS)}

Cow body condition was scored on a 1-9 scale ( 1 = extremely thin to $9=$ extremely fat), illustrated here with photos of cows in condition scores 3,5 , and 7 .

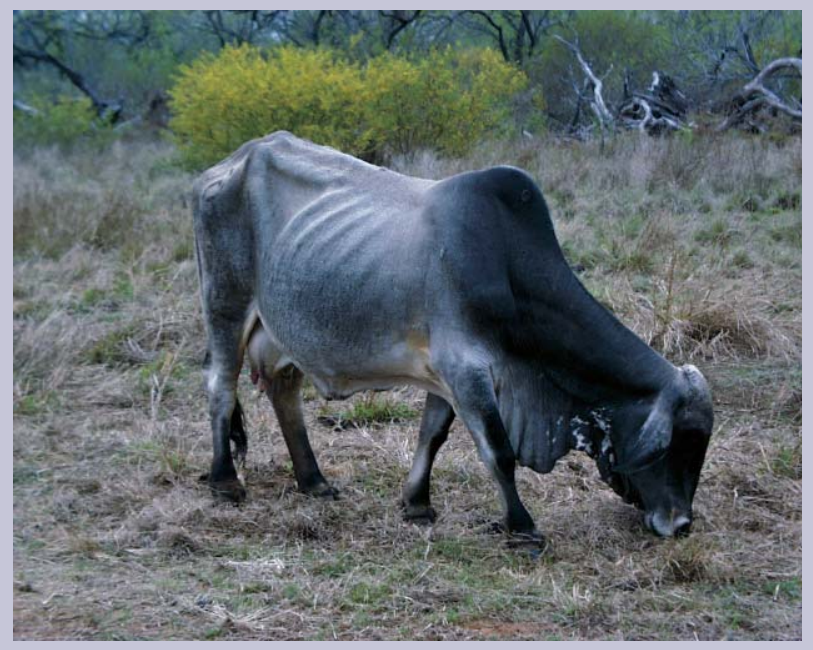

BCS-3 cow. All ribs and backbone are visible.

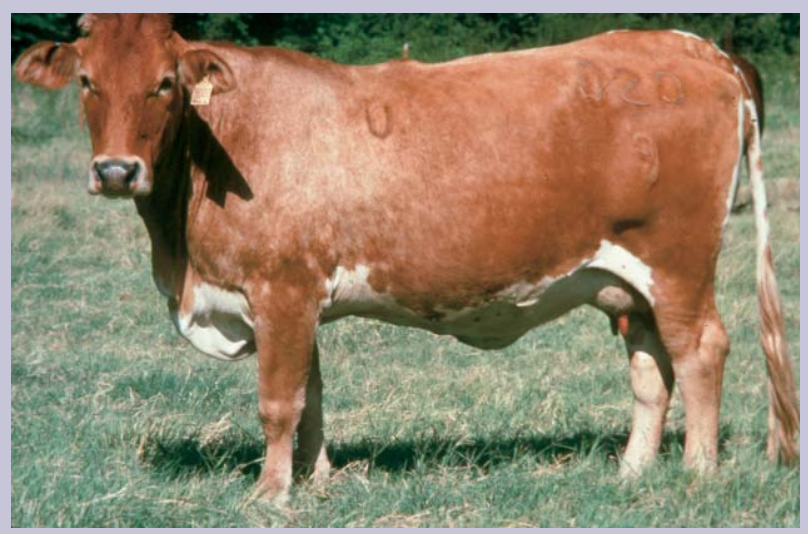

BCS-5 cow. Ribs and backbone are not visible and areas on each side of the tail head are fairly well filled.

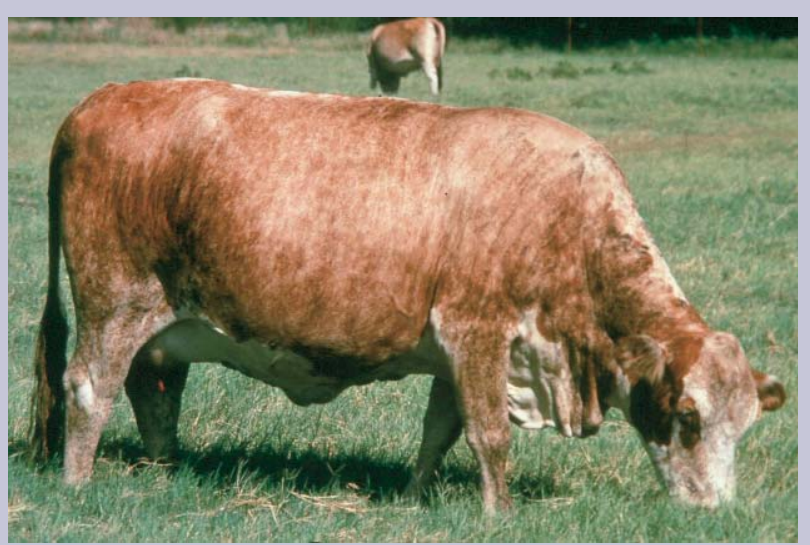

BCS-7 cow. Shows abundant fat cover on either side of the tail head. to estimate crude protein and digestible organic matter content of forage consumed by cows. ${ }^{8}$

\section{Characterizing Cows for the Computer Model}

Herd information including cow production stage (gestation day, lactation day), breed, age, and calf weaning weight and age was collected for use in the computer program. Environmental conditions including current and previous 30-day maximum and minimum daily temperatures and relative humidity levels were estimated. Herd and environmental information and diet quality estimates were entered in the NutBal-PRO computer program ${ }^{9}$ to estimate cow performance for the next 30 days. In this project, maximum temperatures were never set above $29^{\circ} \mathrm{C}\left(85^{\circ} \mathrm{F}\right)$ based on National Research Council ${ }^{10}$ recommendations and previous experience with the computer program. Temperatures above this level tended to overestimate condition score loss.

\section{How Much Do They Eat?}

Each month, computer body-condition score (BCS) estimates using unadjusted (expected) forage intake were compared to observed condition scores. If the computer program overestimated BCS gain and all other information appeared correct, the computer program was rerun reducing forage intake until computer-estimated and observed BCS matched as closely as possible. The adjusted forage intake level required to match observed BCS was recorded as apparent forage intake.

Apparent forage intake was used in 2 ways to calibrate the computer program to the ranch to improve BCS estimates. First, first-year apparent forage intake values for each month were used to predict BCS in the same month during year 2. Second, apparent forage intake values were used to create a cumulative average apparent forage intake value for the past 30 days, which was calculated by averaging apparent forage intake determined for all previous months. These cumulative average apparent forage intake values were

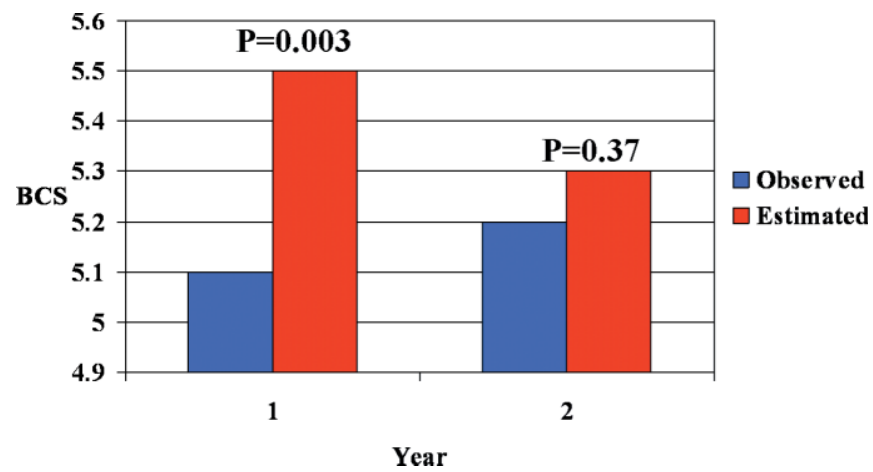

Figure 1. Comparison of average computer-estimated and observed body condition scores (BCS) during year 1 and year 2 on 3 ranches in 4 herds. In year 1, computer-model expected forage intake was used to predict BCS. In year 2, computer estimates for each month were made using apparent forage intake values from corresponding months in year 1 . 
used to determine the pounds of forage intake used in the computer program to estimate $\mathrm{BCS}$ for the next month.

\section{What We Learned Cattle Forage Diet Quality}

Average estimated crude protein of forage consumed across all ranches was $8.9 \%$, whereas average estimated digestibility was $60.4 \%$. Estimated average nutritive value of consumed forage differed among ranches $(P<0.0001)$, with ranges of $8 \%-11 \%$ and $59 \%-62 \%$ for crude protein and digestibility, respectively.

\section{Cow BCS Estimates Using Apparent Forage Intake}

Yearly average BCS estimates using expected forage intake values on 3 ranches and 4 herds were greater than observed BCS (Fig. 1). Using first-year monthly apparent forage intake values to estimate BCS for the same month in year 2, yearly average observed and estimated BCS were similar (Fig. 1).

Although this approach improved BCS estimates, values that could be applied more immediately would be more useful. In addition, because of yearly variation in rainfall and forage production, using monthly forage intake estimates from one year to estimate forage intake during the same month in a future year might not be feasible. For example, in one instance in this project, a difference in apparent forage intake of 15 pounds was observed for the same month in 2 successive years.

Across all 5 ranches and 6 herds, BCS estimates based on cumulative average apparent forage intake (Fig. 2) were not different $(P=0.7757)$ from observed BCS. However, $\mathrm{BCS}$ estimates based on expected forage intake were greater than either observed BCS or estimates using cumulative average apparent intake values.

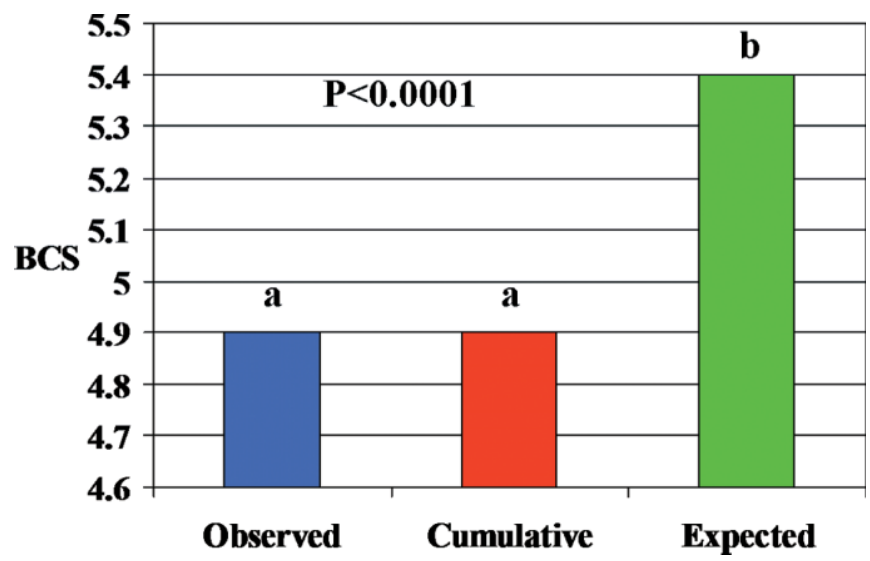

Figure 2. Average observed body condition score (BCS) vs average computer-estimated BCS using expected forage intake and cumulative average apparent forage intake across 5 ranches and 6 herds. Apparent intake was the level where computer-estimated BCS matched observed BCS. Cumulative intake was calculated as the average of all previous monthly apparent forage intake values.

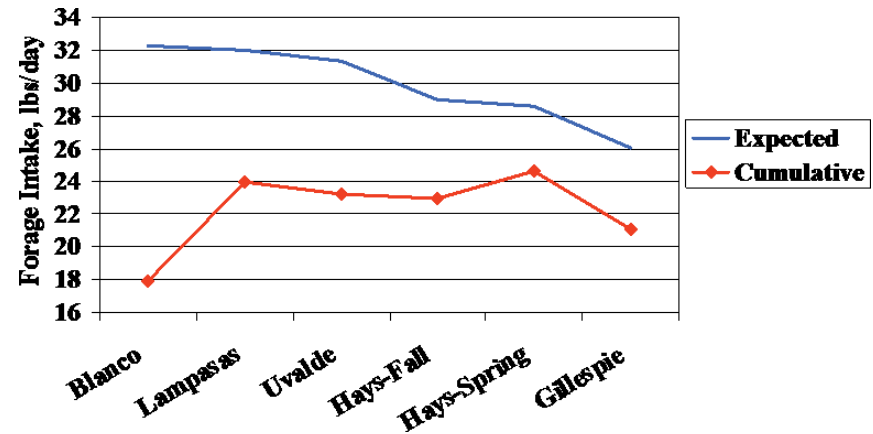

Figure 3. Average expected forage intake differed $(P<0.0001)$ among the 5 study ranches and 6 herds. Cumulative apparent forage intake tended $(P=0.1367)$ to differ among ranches. Apparent intake was the level where computer-estimated body condition score (BCS) matched observed BCS. Cumulative intake was calculated as the average of all previous monthly apparent forage intake values.

BCS estimates using expected forage intake overestimated observed BCS by 0.5 to 1.5 condition score $34 \%$ of the time compared to $9 \%$ for estimates based on cumulative average apparent forage intake. In other words, cows ate less than expected.

\section{Expected vs Apparent Forage Intake}

Average expected forage intake (Fig. 3) differed among ranches. Expected intake averaged 29 pounds per day and varied from 26 to 32 pounds. On a percentage of BCS-5 body-weight basis, average expected intake across all ranches was $2.6 \%$ and varied from $2.3 \%$ to $2.7 \%$ among ranches. Maximum and minimum expected forage intakes were $3.5 \%$ and $1.5 \%$, respectively. These differences were due to differences in cow production levels, weather, and forage digestibility among ranches.

These expected intake levels appear to be reasonable considering the traditional definition of an animal unit. Average annual dry-matter forage intake for an animal unit is 26 pounds per day for a 1,000 -pound cow, or $2.6 \%$ of body weight. Cattle are certainly capable of higher intake levels as demonstrated by a dairy cow that was documented to have consumed $7 \%$ dry matter intake on a body-weight basis. ${ }^{11}$

However, overestimates of BCS using these expected values appear to indicate that these intake levels were generally not achieved among cows in the project herds. This observation is not surprising considering reports of $80 \%$ of grazed diets coming from $1 \%$ to $6 \%$ of the standing crop. ${ }^{2,3}$ Therefore, forage quantity can be nutritionally limiting even if grass standing crop appears adequate.

Apparent forage intake averaged 23 pounds per day and tended to differ (Fig. 3) among ranches with a range from 19 to 24 pounds. As a percentage of body weight, these intake levels were equivalent to an average of $2.0 \%$ with a range of $1.7 \%$ to $2.1 \%$. Maximum apparent intake was $3.1 \%$ of body weight and averaged $2.7 \%$ across ranches, which are close to average expected intake. Minimum apparent forage intake was $1.1 \%$ of body weight. 
These apparent forage intake values are similar to those reported in 2001 by Holechek et al ${ }^{12}$ where average drymatter intake for grazing cattle was about $2 \%$ of body weight with levels ranging from $1.2 \%$ to $2.8 \%$. In Texas, Pinchak et al. ${ }^{13}$ reported forage intake values for cattle of $1.95 \%$ to $2.45 \%$ across a year.

Average expected intake across all ranches was greater than cumulative average apparent intake (Fig. 3). Eightyone percent of expected forage intake values were between 25 and 35 pounds per day compared to $29 \%$ for apparent intake. No expected intake values were below 20 pounds per day, whereas $38 \%$ of apparent intake values were below this level. Average difference between expected and apparent forage intake was 7 pounds and varied from 5 to 13 pounds across ranches.

On study ranches, differences between apparent and expected forage intake explained $44 \%$ of the variation in BCS change. Digestible organic matter estimates explained an additional $13 \%$ of variability for a total of $57 \%$ for the 2 variables combined. Crude protein estimates did not explain any additional variation in BCS change. When apparent forage intake was 7.5 pounds or more below expected forage intake, BCS change tended to be negative.

\section{Implications}

Regarding grazing cattle performance, forage availability and forage intake are as important as forage quality. In fact, forage quantity can be nutritionally limiting even if grass standing crop appears adequate. Cows in belly-deep grass can be hungry.

The approach used in this project of combining 1) forage diet quality estimates from NIRS fecal analysis, 2) the NutBal PRO computer model to describe animal and environmental variables affecting performance, and 3) body-condition scoring to estimate apparent forage intake improved animal performance estimates.

Using unadjusted forage intake estimates, the computer model overestimated cow BCS by more than 0.5 condition score about $34 \%$ of the time. However, using apparent intake calculated as a cumulative average, differences between computer-estimated and observed condition scores were less than 0.5 about $90 \%$ of the time.

From a practical standpoint, it is difficult to visually estimate less than a 0.5 condition-score difference (40 to 50 pounds of body weight). Therefore, using cumulative average forage intake provided adequate accuracy.

This approach provides a practical way to get reasonable estimates of forage intake and calibrate forage intake to individual ranches. Therefore, this approach is a valuable tool for nutritional analyses to distinguish between forage quality and quantity as limiting nutritional factors.

\section{References}

1. Fox, D. G. 1995. Application of the Cornell net carbohydrate and protein system for predicting the nutrient requirements of beef cattle. Proceedings of Mid-South Ruminant Nutrition Conference; 4-5 May 1995; Dallas, TX. College Station, TX: Texas Agricultural Extension Service. 9 p.

2. Arnold, G. W., And M. L. Dudzinski. 1978. Ethology of free-ranging domestic animals. New York, NY: Elsevier. $198 \mathrm{p}$.

3. Cruz, R., and D. Ganskopp. 1998. Seasonal preferences of steers for prominent northern Great Basin grasses. Journal of Range Management 51:557-565.

4. Kirby, D. R., and J. W. Stuth. 1982. Botanical composition of cattle diets grazing brush managed pasture in east-central Texas. Journal of Range Management 35:434-436.

5. O'Reagain, P. J., And E. A. Grau. 1995. Sequence of species selection by cattle and sheep on South African sourveld. Journal of Range Management 48:314-321.

6. Moore, J. E. 1996. Practical approaches to estimating pasture intake. In: R. E. Joost and C. A. Roberts [EDs.]. Proceedings, nutrient cycling in forage systems. Columbia, MO: Center for Pasture Management, University of Missouri. p. 193. Cited in Macoon et al. (2003).

7. Macoon, B., L. E. Sollengerger, J. E. Moore, C. R. Staples, J. H. Fike, and K. M. Portier. 2003. Comparison of three techniques for estimating the forage intake of lactating dairy cows on pasture. Journal of Animal Science 81:2357-2366.

8. Lyons, R. K., And J. W. Stuth. 1992. Fecal NIRS equations for predicting diet quality of free-ranging cattle. Journal of Range Management 45:238-244.

9. NutBal PRO [computer program]. 2002. College Station, TX: Ranching Systems Group, Texas A\&M University.

10. National Research Council. 1996. Nutrient requirements of beef cattle. 7th ed. Washington, DC: National Academy Press. $242 \mathrm{p}$.

11. Schingoethe, D. J., F. M. Byers, and G. T. Schelling. 1988. Nutrient needs during critical periods of the life cycle. In: D. C. Church [ED.]. The ruminant animal: Digestive physiology and nutrition. Englewood Cliffs, NJ: Prentice Hall. p 421-447.

12. Holecheck, J. L., R. D. Pieper, and C. H. Herbel. 2001. Range management: Principles and practices. Upper Saddle River, NJ: Prentice Hall. 587 p.

13. Pinchak, W. E., S. C. Canon, R. K. Heitschmidt, and S. Dowher. 1990. Effects of long-term year-long grazing at moderate and heavy rates of stocking on diet selection and forage intake dynamics. Journal of Range Management 43:304309.

Authors are Professor and Extension Range Specialist, Department of Ecosystem Science and Management, Texas Cooperative Extension, Texas A $\Xi^{M} M$ University Research and Extension Center, Uvalde, TX 78802-1849, rk-lyons@tamu. edu (Lyons); and Professor and Extension Livestock Specialist, Department of Animal Science, Texas Cooperative Extension, Texas A $\mathcal{G}^{M} M$ University Research and Extension Center, Uvalde, TX 78802-1849 (Machen). 